\title{
Arquitetura da informação no contexto da informação em saúde: um olhar para o website da Covid-19 no Brasil
}

\section{Information architecture in the context of health information: an analysis of the Brazilian Covid-19 website}

\author{
Jean Fernandes Brito ${ }^{1}$, Rafaela Carolina da Silva ${ }^{2}$, Beatriz Rosa Pinheiro Santos ${ }^{3}$, Mariana Rodrigues Gomes de \\ Mello $^{4}$, Daniel Martínez-Ávila ${ }^{5}$ \\ ${ }^{1}$ Universidade Estadual Paulista Júlio de Mesquita Filho - UNESP, Marilia, SP, Brasil. ORCID: https://orcid.org/0000-0002-9258-8205 \\ 2 Universidade Estadual Paulista Júlio de Mesquita Filho - UNESP, Marília, SP, Brasil. ORCID: https://orcid.org/0000-0001-9684-0327 \\ ${ }^{3}$ Universidade Estadual Paulista Júlio de Mesquita Filho - UNESP, Marília, SP, Brasil. ORCID: https://orcid.org/0000-0001-8620-2612 \\ ${ }^{4}$ Universidade Estadual Paulista Júlio de Mesquita Filho - UNESP, Marília, SP, Brasil. ORCID: https://orcid.org/ 0000-0002-5925-8554 \\ 5 Universidade Estadual Paulista Júlio de Mesquita Filho - UNESP, Marília, SP, Brasil / Carlos III de Madrid - Espanha. ORCID: \\ https://orcid.org/0000-0003-2236-553X
}

Autor para correspondência/Mail to: Jean Fernandes Brito, j.brito@unesp.br

Recebido/Submitted: 08 de julho de 2020; Aceito/Approved: 17 de novembro de 2020

Copyright (c) 2020 Brito, Siva, Santos, Mello \& Martínez-Ávila. Todo o conteúdo da Revista (incluindo-se instruções, política editorial e modelos) está sob uma licença Creative Commons Atribuição-NãoComercial-Compartilhalgual 3.0 Não Adaptada. Ao serem publicados por esta Revista, os artigos são de livre uso em ambientes educacionais, de pesquisa e não comerciais, com atribuição de autoria obrigatória. Mais informações em http://revistas.ufpr.br/atoz/about/submissions\#copyrightNotice.

\begin{abstract}
Resumo
Introdução: a pesquisa avalia a página principal do ambiente informacional digital do site do governo federal brasileiro sobre a COVID-19, a partir da ótica da arquitetura da informação, a fim de contribuir para uma recuperação da informação efetiva dos sujeitos informacionais que navegam nesse ambiente. Metodologia: estudo de natureza qualitativa, de cunho exploratório e aplicado que utiliza a Netnografia como método para a investigação e descrição do objeto de estudo. Resultados: foram levantados cinco pontos positivos e cinco pontos negativos do ambiente informacional digital analisado. Como representação dos pontos positivos, o website apresenta um painel com notícias atualizadas sobre o tema e como representação dos pontos negativos, nota-se a omissão de dados e ausência de um sistema de busca na página principal. Conclusão: a partir dos pontos levantados na análise, propôs-se um wireframe para a página principal do website da COVID-19 no Brasil.
\end{abstract}

Palavras-chave: Arquitetura da informação; COVID-19; Informação em saúde; Recuperação da informação; Sistema único de saúde.

\begin{abstract}
Introduction: this paper assesses the home page of the digital informational environment of the Brazilian federal government website on COVID-19 from the perspective of information architecture. It aims to contribute to effective information retrieval for the informational subjects that browse this environment. Method: a qualitative, exploratory, and applied study uses the netnography as a method for the investigation and description of the object of study. Results: we found five positive points and five negative points in the studied digital information environment. As an example of the positive points, the website presents a panel with updated news on the topic and as an example of the negative points the omission of data and a search box on the home page. Conclusions: Based on the results, a wireframe for the home page of the COVID-19 website in Brazil is proposed.
\end{abstract}

Keywords: Information architecture; COVID-19; Health information; Information retrieval; Unified health system.

\section{INTRODUÇÃO}

A saúde é um direito social com previsão constitucional e inerente da condição humana, sem o qual não se pode falar em vida digna (Constituição da República Federativa do Brasil de 1988, 2019). Para garantir esse direito fundamental, é necessário o acesso às informações de saúde em duplo aspecto: tanto para que os cidadãos possam ser informados acerca dos serviços disponíveis e seus direitos, quanto para oferecerem dados ao Estado sobre a população e seu modo de vida, a fim de que ele possa estabelecer políticas públicas que atendam às demandas de saúde em cada local.

Nesta perspectiva, as mídias escritas, televisivas e relacionadas a todo universo que envolve a internet assumiram um papel importante na conscientização dos cidadãos, tornando-se canais de apelo coletivo e de cobrança de responsabilidade individual em momentos como o da pandemia do novo coronavírus, ou COVID-19.

Sob este aspecto, é inegável que o acesso à informação de saúde na internet, na atualidade, deve ser tratado como uma questão de saúde pública. Para tanto, os websites governamentais são fundamentais, na medida em que são vias fidedignas na busca da informação e, assim, precisam ter uma arquitetura eficiente, que favoreça o acesso da população às informações ali contidas.

Posto isto, esta pesquisa parte do seguinte questionamento: como o website da COVID-19 está estruturado, em termos de Arquitetura da Informação, com vistas a otimizar o acesso às informações de saúde aos sujeitos 
informacionais? Alinhado ao problema de pesquisa, apresenta-se como objetivo geral avaliar a página principal do website do Governo Federal brasileiro acerca da COVID-19, sob a ótica da Arquitetura da Informação, de modo a apresentar uma recuperação da informação efetiva aos sujeitos informacionais que ali navegam. Os objetivos específicos são: a) identificar os pontos positivos e negativos do website da COVID-19 no Brasil o que você precisa saber e como prevenir o contágio e b) propor um wireframe da página principal com uma nova arquitetura para o website da COVID-19 no Brasil.

Metodologicamente, trata-se de uma pesquisa de natureza qualitativa, de cunho exploratório e aplicado, utilizando o método da Netnografia para a investigação e descrição do objeto de estudo. Portanto, o caráter exploratório e aplicado, bem como o contexto letal de uma pandemia nos moldes da COVID-19, aliados à necessidade de informação urgente e segura sobre saúde, justifica a relevância do estudo proposto.

\section{INFORMAÇÃO EM SAÚDE, COMPORTAMENTO INFORMACIONAL E COMPETÊNCIA EM INFORMAÇÃO}

Os estudos relativos à informação em saúde envolvem a inter-relação entre dois campos científicos: Ciência da Saúde e Ciência da Informação que, juntos, contribuem para a melhor formação da sociedade, representada por indivíduos que necessitam de um comportamento informacional pautado pela competência em informação, principalmente quando o assunto é saúde pública e autocuidado. Entretanto, o envolvimento entre essas duas áreas não se finaliza apenas entre elas, ou seja, não é nada fixo, tampouco permanente. A Tecnologia da Informação, por muitas vezes, se encaixa nesses movimentos de inter-relação entre a Ciência da Saúde e a Ciência da Informação, com o intuito de contribuir para o alcance da competência em informação que se espera da população assistida e das organizações de saúde que assistem tal população.

De acordo com Yafushi (2015):

[...] a competência em informação está relacionada ao "saber", como acessar, diagnosticar, usar, recuperar, tratar, reter, descartar, interpretar e gerenciar as informações, não só por meio de bases de dados disponibilizados na internet, mas também das bases humanas, compartilhando e trocando conhecimento entre os usuários/colaboradores; essa é a técnica atrelada à prática, resultando em tomada de decisões assertivas e mais crítica (Yafushi, 2015, p. 205-206).

Para Santos (2019), a competência em informação é uma ferramenta útil para o ensino, para a formulação de estratégias e para o diferencial competitivo de organizações, uma vez que valoriza a informação desde sua percepção até o seu uso competente, a fim de que os gestores sejam capazes de identificar a necessidade do usuário ou a própria necessidade de informação e aplicar as informações acessadas no problema envolvido à necessidade. Além disso, para a autora, a competência em informação contribui com a potencialização do processo de Gestão da Informação, auxiliando nos processos organizacionais mediante a estruturação e consolidação das informações e consequente geração de conhecimentos que, quando adquiridos, processados e internalizados, geram transformações contínuas e positivas entre os sujeitos informacionais.

\begin{tabular}{|c|c|c|c|}
\hline Dimensão Técnica & Dimensão Estética & Dimensão Ética & Dimensão Política \\
\hline $\begin{array}{l}\text { Meio de ação no con- } \\
\text { texto da informação }\end{array}$ & Criatividade sensível. & $\begin{array}{l}\text { Uso responsável da in- } \\
\text { formação. }\end{array}$ & Exercício da cidadania. \\
\hline $\begin{array}{l}\text { Consiste nas habilida- } \\
\text { des adquiridas para en- } \\
\text { contrar, avaliar e usar a } \\
\text { informação de que pre- } \\
\text { cisamos. }\end{array}$ & $\begin{array}{l}\text { Capacidade de compre- } \\
\text { ender, relacionar, orde- } \\
\text { nar, configurar e ressig- } \\
\text { nificar a informação. }\end{array}$ & $\begin{array}{l}\text { Visa a realização do } \\
\text { bem comum. }\end{array}$ & $\begin{array}{l}\text { Participação dos indi- } \\
\text { víduos nas decisões e } \\
\text { nas transformações re- } \\
\text { ferentes à vida social. }\end{array}$ \\
\hline $\begin{array}{l}\text { Ligada à ideia de que } \\
\text { o indivíduo compe- } \\
\text { tente em informação } \\
\text { é aquele capaz de } \\
\text { acessar com sucesso } \\
\text { e dominar as novas } \\
\text { tecnologias. }\end{array}$ & $\begin{array}{l}\text { Experiência interior, in- } \\
\text { dividual e única do su- } \\
\text { jeito ao lidar com os } \\
\text { conteúdos de informa- } \\
\text { ção e sua maneira de } \\
\text { expressá-la e agir sobre } \\
\text { ela no âmbito coletivo. }\end{array}$ & $\begin{array}{l}\text { Relaciona-se a ques- } \\
\text { tões de apropriação } \\
\text { e uso da informação, } \\
\text { tais como propriedade } \\
\text { intelectual, direitos } \\
\text { autorais acesso à infor- } \\
\text { mação e preservação } \\
\text { da memória do mundo. }\end{array}$ & $\begin{array}{l}\text { Considera que a infor- } \\
\text { mação é produzida a } \\
\text { partir de (e em) um con- } \\
\text { texto específico. }\end{array}$ \\
\hline
\end{tabular}

Quadro 1. Resumo das dimensões sociais da Colnfo.

Fonte: Vitorino e Piantola (2011, p. 109).

Na Quadro 1, Vitorino e Piantola (2011) apresentam quatro dimensões sociais da competência em informação: dimensão técnica, dimensão estética, dimensão ética e dimensão política. Tais dimensões podem ser utilizadas pelo campo da Informação em Saúde com o intuito de promover informações precisas, compreensíveis, diretivas e 
que resolvam problemas de acesso, de auto prevenção e de consciência da população com relação à importância da qualidade na saúde pública. Do ponto de vista da dimensão técnica, o sujeito competente em informação aprende e adquire habilidades para encontrar, avaliar e usar a informação de que precisa. Na dimensão estética, o sujeito competente em informação aprende e possui capacidade de compreender, relacionar, ordenar, configurar e ressignificar a informação para o seu uso. Na dimensão ética, o sujeito é tido como competente em informação quando ele a utiliza em prol do bem comum de outras pessoas, assim como a informação que é produzida e compartilhada deve visar o êxito de todos que a consomem. Por último, a dimensão política acredita que o sujeito competente em informação deve participar das decisões e das transformações sociais e, portanto, defende o acesso democrático à informação.

Segundo Spink e Case (2012), o comportamento informacional pode ser definido como um processo de busca de informação ativa e passiva para aquisição de informação, ou seja, o indivíduo pode sentir a necessidade de buscar uma informação, perceber essa necessidade, buscar a informação necessária e acessá-la, assim como pode acessar determinada informação que chega até ele, mas que não foi requerida e buscada propositalmente por esse indivíduo.

O comportamento informacional também se dá mediante os padrões de consumo e uso da informação e, para Murray (1991), o consumidor tende a buscar mais informação antes de utilizar um produto ou serviço se perceber algum risco relativo à sua segurança e funcionamento, bem como algum prejuízo financeiro, entre outros. Dessa maneira, na maioria das vezes, o comportamento de busca de informação se dá quando existem problemas ou "dores" sofridas pelo sujeito de ação da busca informacional.

Sabe-se que o consumo de informação também tem preço, e se tem preço é necessário o mínimo de poder aquisitivo para esse consumo, encontrados em jornais, revistas, livros, meios de comunicação e revistas científicas, que nem sempre são de acesso aberto ao público. Portanto, o poder aquisitivo também determina o comportamento informacional do indivíduo que necessita de acesso à informação para sobreviver e para exercer sua própria cidadania. Essa é uma luta constante dos ambientes e dos profissionais que trabalham com a informação e com a saúde, tendo em vista que buscam promover um acesso democrático e de qualidade com relação ao autocuidado e à prevenção de agravos e doenças. É por isso que o Sistema Único de Saúde (SUS), enquanto ofertante de informação e conhecimento abertos ao público, torna-se importante do ponto de vista democrático.

Ademais, o comportamento informacional de busca e acesso à informação não diz respeito apenas às fontes formais, explícitas e documentadas; essas fontes também podem ser tácitas (Wilson, 1997) e expressas em diferentes tipos de conteúdo, como imagens, infográficos, áudios, vídeos etc. Diante desse contexto, a tecnologia da informação e, mais precisamente, a arquitetura da informação, insere-se como um campo de estudo que possui o intuito de organizar todo esse conteúdo em formato web para uma comunicação efetiva com o usuário/sujeito que busca, recupera e acessa informações em ambientes informacionais digitais.

\section{ARQUITETURA DA INFORMAÇÃO}

A Arquitetura da Informação tem suas bases teóricas alicerçadas na Biblioteconomia, Ciência da Informação e Ciência da Computação, fornecendo abordagens teóricas e práticas para a estruturação de ambientes informacionais digitais. A Arquitetura da Informação pode ser estabelecida como:

(i) Projeto estrutural de ambientes de informações compartilhados. (ii) A combinação de organização, rotulagem, busca e sistemas de navegação em websites e Intranets. (iii) A arte e ciência de modelar produtos informativos e experiências para duas habilidades: a de usar e a de encontrar. (iv) A Arquitetura da Informação é uma disciplina emergente focada em princípios de projeto de arquitetura para ambiente digital (Rosenfeld, Morville, \& Arango, 2015, p. 4).

Para a construção de um website que satisfaça as necessidades dos sujeitos informacionais, recomenda-se o trabalho em conjunto com uma equipe multidisciplinar, com olhares diferenciados, a fim de perceber e compreender estruturas e, assim, facilitar a representação da informação e a garantia de sua recuperação. Logo, pode-se dizer que a Arquitetura da Informação auxilia no planejamento de protótipos de ambientes digitais ("wireframe"), determinando espaços de acordo com o grau de relevância de cada uma das informações a serem disponibilizadas. Essa relevância pode e deve ser determinada por uma pesquisa entre usuários.

Pesquisadores como Rosenfeld et al. (2015), Camargo e Vidotti (2011) e Vechiato e Vidotti (2009) apresentam a Arquitetura da Informação por meio de uma abordagem que integra elementos de Organização, Navegação, Rotulagem, Busca. No Quadro 2 apresenta-se a definição de cada sistema: 


\begin{tabular}{|l|l|}
\hline Sistemas & Definição \\
\hline Organização & $\begin{array}{l}\text { Tem como finalidade distribuir o conteúdo no web- } \\
\text { site, utilizando as formas de organização através de } \\
\text { Esquemas e Estruturas. }\end{array}$ \\
\hline Navegação & $\begin{array}{l}\text { Permite uma interação do website com o usuário, fa- } \\
\text { vorecendo caminhos que facilitem a obtenção da in- } \\
\text { formação procurada. }\end{array}$ \\
\hline Rotulagem & $\begin{array}{l}\text { Possui informações que podem ser acessadas através } \\
\text { de palavra ou ícone que auxiliam na identificação o } \\
\text { conteúdo. }\end{array}$ \\
\hline Busca & $\begin{array}{l}\text { É responsável pelo acesso rápido à informação con- } \\
\text { tida no website. }\end{array}$ \\
\hline
\end{tabular}

Quadro 2. Apresentação e definição dos sistemas da Arquitetura da Informação. Fonte: Rosenfeld et al. (2015).

Além dos sistemas apresentados, entende-se, nesta pesquisa, que a acessibilidade centra o processo da Arquitetura da Informação, de modo a promover uma inclusão efetiva aos sujeitos informacionais. Nesse sentido, o [..] "usuário deve interagir facilmente (usabilidade) com autonomia no acesso e uso do conteúdo (acessibilidade) no ambiente hipermídia informacional digital" (Vidotti, Cusin, \& Corradi, 2008, p. 182).

Todos os elementos que compõem a Arquitetura da Informação se relacionam de forma sistêmica, promovendo, aos sujeitos informacionais, uma busca e recuperação efetiva da informação. Ferreira (2018) explica que:
A Arquitetura da Informação de ambientes digitais, de acordo com sua visão global, auxilia no desenvolvimento do projeto de ambientes informacionais, e oferece recursos para a construção da planta baixa, frameworks, com foco na categorização, classificação, armazenamento. Considerando os ambientes informacionais como sistemas complexos, outros tantos recursos podem ser agregados para melhorar a interação dos usuários com esses ambientes (Ferreira, 2018, p. 93).

Assim, a estrutura de um website "[...] tem subsídios na Arquitetura da informação para o desenvolvimento da estratégia, e do projeto que deve ser desenvolvido a partir do levantamento das características dos usuários que irão utilizar o ambiente" (Ferreira, 2018, p. 101). Na visão de Vechiato (2010) a Arquitetura da Informação se posiciona com o comportamento informacional, na medida em que alia o processo de organização, navegação e busca dos sujeitos informacionais nos ambientes informacionais digitais. Nesse ínterim, os autores Vechiato e Vidotti (2009) discorrem que o comportamento informacional no contexto da Arquitetura da Informação "permite o levantamento das necessidades informacionais e fontes de informação mais utilizadas pelas pessoas e o estudo do comportamento de busca e uso da informação, possibilitando a definição de interface e conteúdo do ambiente informacional digital" (Vechiato \& Vidotti, 2009, p. 289, grifo nosso).

A necessidade de informação, ora apresentada, é o ponto chave para que os sujeitos informacionais naveguem e encontrem as informações que precisam. No âmbito da informação e saúde, como enfoque deste trabalho, o comportamento dos sujeitos se debruça em uma essencialidade que supra todas as informações acerca dessa temática, em especial a da COVID-19. Tendo em vista esse cenário, Vechiato e Vidotti (2009, p. 143) explicam "que quando um produto é projetado, é preciso refletir sobre quantos usuários são impedidos de usar e acessar determinada informação". Tal reflexão corrobora com a análise de ambientes informacionais digitais na área da saúde, pois atinge sujeitos informacionais das mais variadas idades e com necessidades específicas, fazendo com que os sistemas da Arquitetura da Informação sejam repensados e revistos.

Na próxima seção serão apresentados os aspectos e os percursos metodológicos para o desenvolvimento, a coleta e a análise de dados da pesquisa.

\section{ASPECTOS METODOLÓGICOS}

Este estudo possui natureza qualitativa, do tipo exploratória e aplicada, tendo como escopo a técnica da observação direta não participante e o método da Netnografia para a coleta e análise dos dados. A Netnografia é um ramo da etnografia que estuda as tecnologias e o comportamento de grupos sociais na internet (Almeida, Sousa, \& Oliveira, 2018), podendo ser também aplicada à análise de sites. No caso desta pesquisa, a Netnografia foi utilizada para a análise e descrição do universo de pesquisa.

A "investigação exploratória é realizada em área na qual há pouco conhecimento acumulado e sistematizado. [...] É, normalmente, o primeiro passo para quem não conhece suficientemente o campo que pretende abordar" (Moresi, 2003, p. 9). Desse modo, a escolha pelo tipo de pesquisa exploratória decorreu do fato de a convergência dos assuntos Arquitetura da Informação, Informação e Saúde e COVID-19 ser um tema novo. Isso ocorre devido 
às circunstâncias que o cenário da pandemia COVID-19 impôs às populações do mundo todo, como também à importância da devida disponibilização de informações acerca da doença para manter a sociedade informatizada.

O universo de estudo abarcou o website "COVID-19 no Brasil: Corona vírus: o que você precisa saber e como prevenir o contágio" e, por meio de uma observação direta não participante, buscou-se analisar os seguintes elementos da Arquitetura da Informação: organização, navegação, rotulagem, busca e acessibilidade. A observação direta é uma técnica qualitativa "[...] com raízes na pesquisa etnográfica tradicional. [...] Essa abordagem permite ao pesquisador [...] utilizar o contexto sociocultural do ambiente observado [...] para explicar os padrões observados de atividade humana" (Marietto, 2018, p. 7-8).

Trata-se de uma observação direta não participante, porque os pesquisadores não se inseriram no ambiente natural de desenvolvimento do ambiente informacional analisado, não envolvendo a comunidade na análise proposta, mas, tão somente realizou-se uma observação da plataforma já disponibilizada em ambiente web. Assim, tendo em vista que o ambiente informacional é uma plataforma virtual criada por pessoas e para pessoas, a metodologia aqui delineada se aplica ao objetivo de estudo proposto.

Para o desenvolvimento de uma nova arquitetura para o website, utilizou-se o software de wireframing Axure (UX), versão 9. Justifica-se a sua escolha por essa ser uma ferramenta de prototipagem rápida, composta de documentação e especificação interativa, destinada a aplicativos da web, móveis e desktop, que visem à experiência do usuário.

Para a análise da acessibilidade do site foi utilizado o software Access Monitor Plus, um validador automático de acessibilidade na web, vinculado ao World Wide Web Consortium (W3C). Ressalta-se que a análise dos dados se delimitou ao formato desktop. A coleta de dados no ambiente informacional ocorreu no período de 9 a 22 de junho de 2020 .

\section{ANÁLISE E DISCUSSÃO DOS RESULTADOS}

Nesta seção é apresentado o website do COVID 19, no qual se analisou a sua página principal, sob a ótica dos elementos da Arquitetura da Informação, bem como seus pontos positivos e negativos. Por fim, segue-se a proposta de um novo wireframe para o ambiente informacional digital.

\section{Análises da arquitetura no website da covid-19}

O ambiente informacional digital da COVID-19, desenvolvido pelo Ministério da Saúde, foi criado em 2020 com o intuito de disponibilizar dados e informações sobre o novo coronavírus no Brasil. A seguir, apresenta-se a análise dos elementos da Arquitetura da Informação da página: Sistema de organização, Sistema de Navegação, Sistema de Rotulagem e Sistema de Busca.

a) Sistema de organização

No que condiz ao sistema de organização, verificou-se a existência dos seguintes elementos: distribuição por tópicos e direcionamento a públicos em geral. Em relação à estrutura do ambiente, essa apresenta estrutura de teias hipertextuais. A Figura 1 representa um exemplo de coleta de dados.

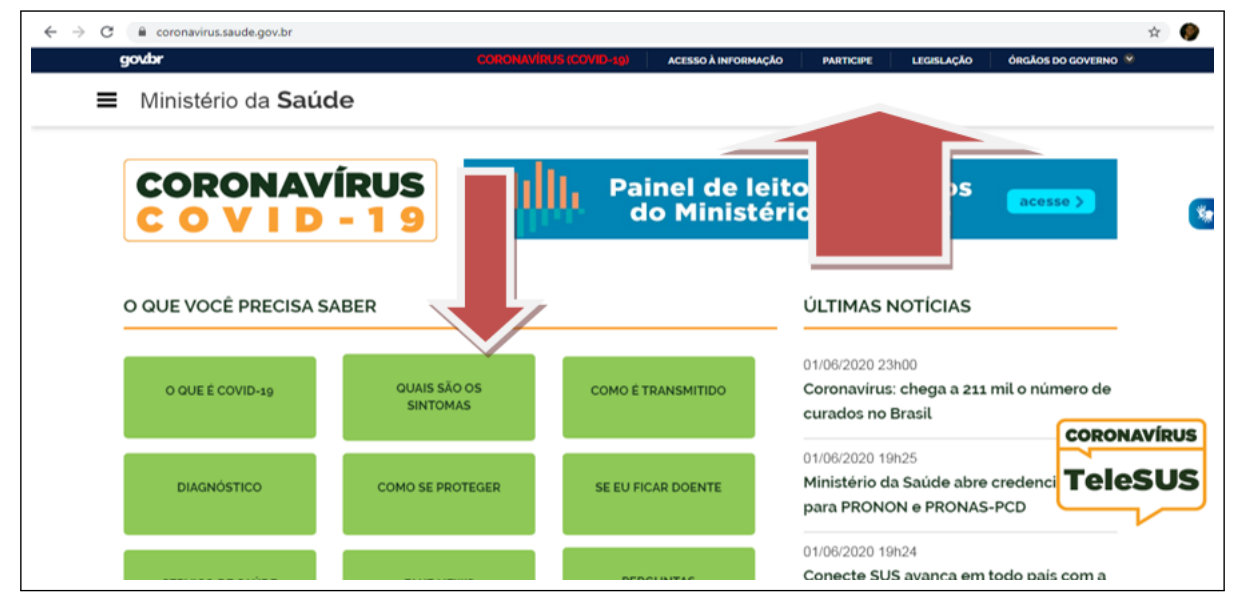

Figura 1. Coleta no Sistema de Organização.

Fonte: Ministério da Saúde (2020).

O website é organizado por blocos de informação, quais sejam: "o que é COVID-19", "quais são os sintomas", "como é transmitido", "se eu ficar doente", entre outros. Na parte superior aparecem "acesso à informação", "participe", "legislação" e "órgãos do governo". 
Além disso, o ambiente informacional apresenta uma estrutura hipertextual e heterogênea, levando-se em conta que esse oferece uma diversidade de formas de conteúdo, bem como conteúdos organizados por tópicos específicos e classes de subordinação, direcionando o usuário aos outros ambientes de informação em saúde propostos pelo Ministério da Saúde.

b) Sistema de navegação

O sistema de navegação permite que os sujeitos informacionais se locomovam dentro do ambiente informacional, por meio de pistas que facilitam o entendimento da organização da informação apresentada pelos menus. Na Figura 2 apresenta-se a coleta de dados no que concerne ao sistema de navegação:

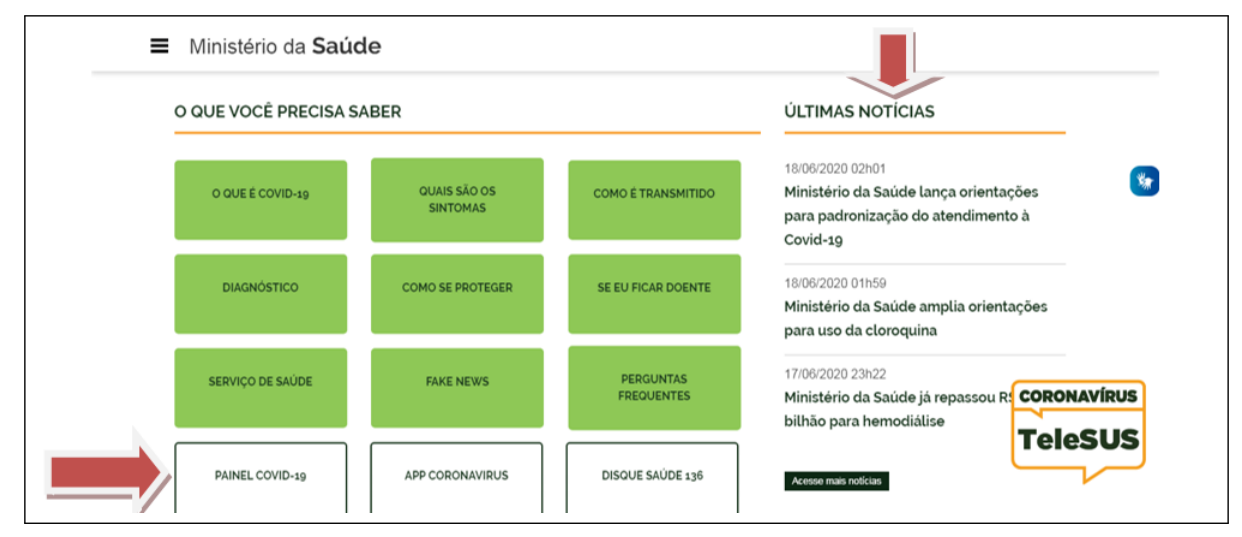

Figura 2. Sistema de Navegação.

Fonte: Ministério da Saúde (2020).

Em destaque ao Sistema de Navegação, pode-se sinalizar a possibilidade de navegação global, ou seja, com informações fora do ambiente digital, como o "Painel COVID-19", "App Coronavírus" e "Disque Saúde". Além disso, os sujeitos podem navegar pelas últimas notícias da pandemia, sendo que o website apresenta orientações e medidas de prevenção da doença.

Na Figura 3 são analisadas as outras formas de navegação que o ambiente permite, destacando- se: "o que você precisa saber", "transparência", e "profissional e gestor".

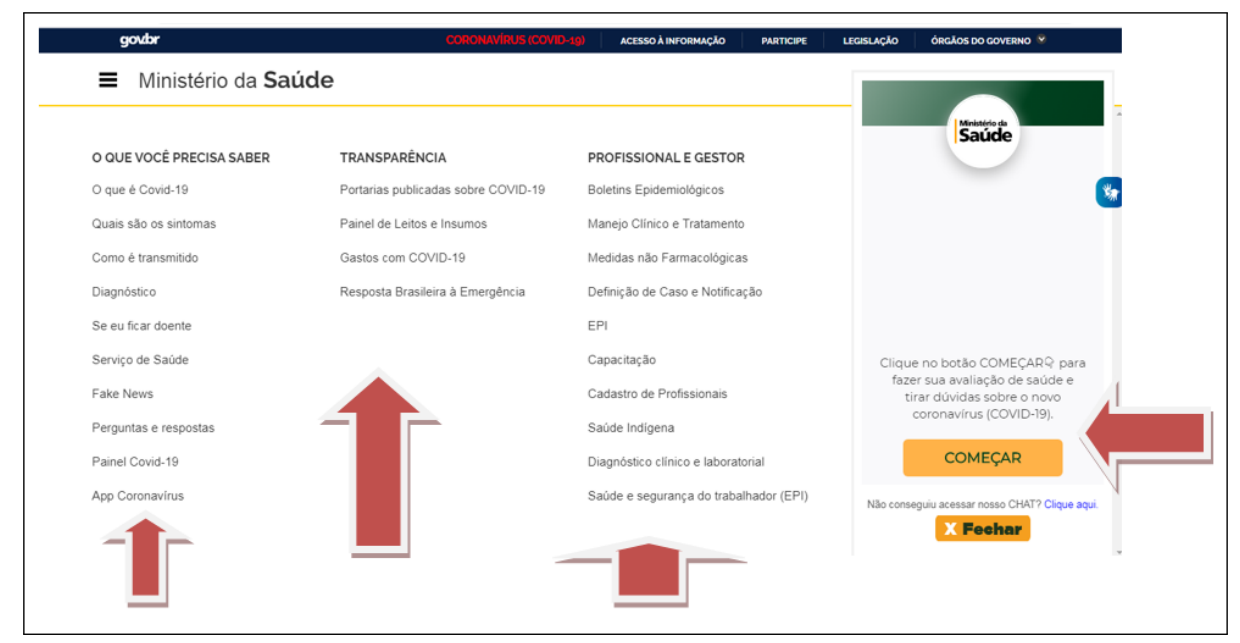

Figura 3. Coleta de dados - Sistema de Navegação.

Fonte: Ministério da Saúde (2020).

Um ponto a se destacar é o chat "TeleSus", no qual é possível que o indivíduo faça uma avaliação sobre a sua saúde, além de tirar dúvidas com os médicos e especialistas da área da saúde sobre o novo coronavírus.

c) Sistema de rotulagem

O sistema de rotulagem analisado, Figura 4, em sua maioria rótulos textuais e, minimamente, rótulos iconográficos e imagéticos, dificulta, por exemplo, o entendimento de nomes específicos da área da saúde. 


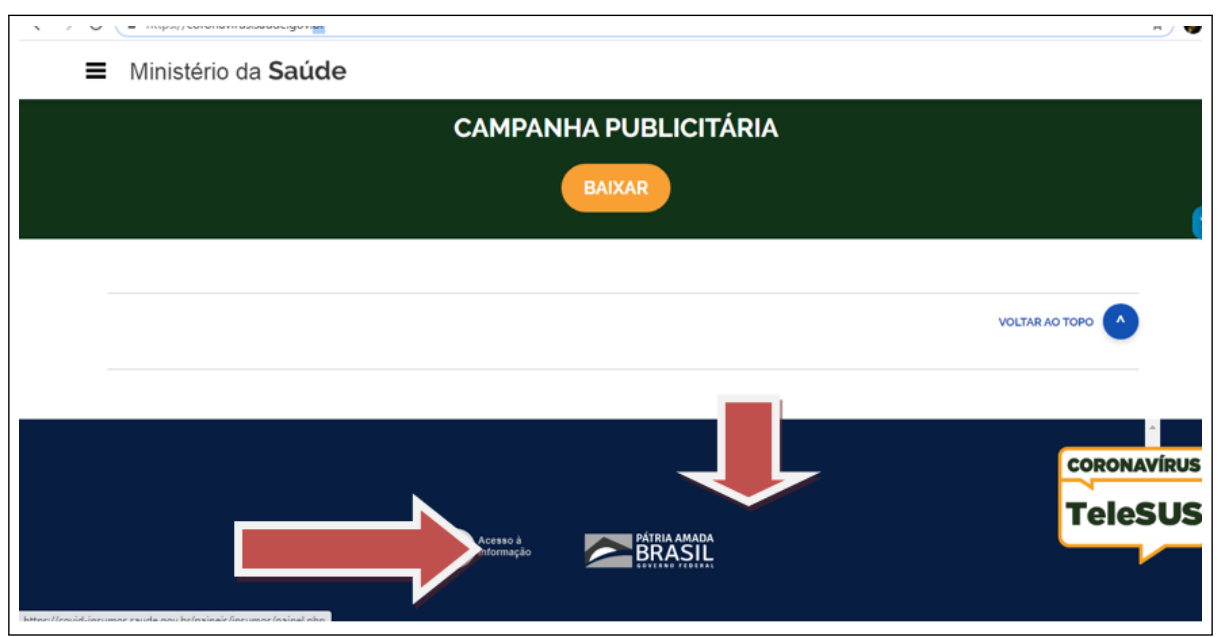

Figura 4. Sistema de Rotulagem.

Fonte: Ministério da Saúde (2020).

Os rótulos apresentados na Figura 4 representam o símbolo do acesso à informação e o novo logotipo do Governo Federal, estando inseridos dentro dos sistemas de organização e navegação. O sistema de rotulagem com conteúdo para o público em geral deve ser repensado de maneira significativa, com ilustrações e avisos sonoros para que os sujeitos entendam e acessem as informações de maneira interativa.

d) Sistema de busca

O último sistema analisado é o Sistema de Busca, o que contribui para a localização e acesso rápido das informações desejadas pelos sujeitos informacionais. O ambiente informacional analisado não possui um sistema de busca, o que dificulta a otimização e recuperação dos conteúdos informacionais nele expressos.

e) Acessibilidade

Em relação à acessibilidade, a ferramenta Access Monitor ${ }^{1}$ avaliou um índice de 5.6 para o ambiente informacional da COVID-19, conforme mostra a Figura 5, além de identificar vários erros por nível de aceitáveis, não aceitáveis e informações para se ver manualmente, que se descrevem seguidamente:

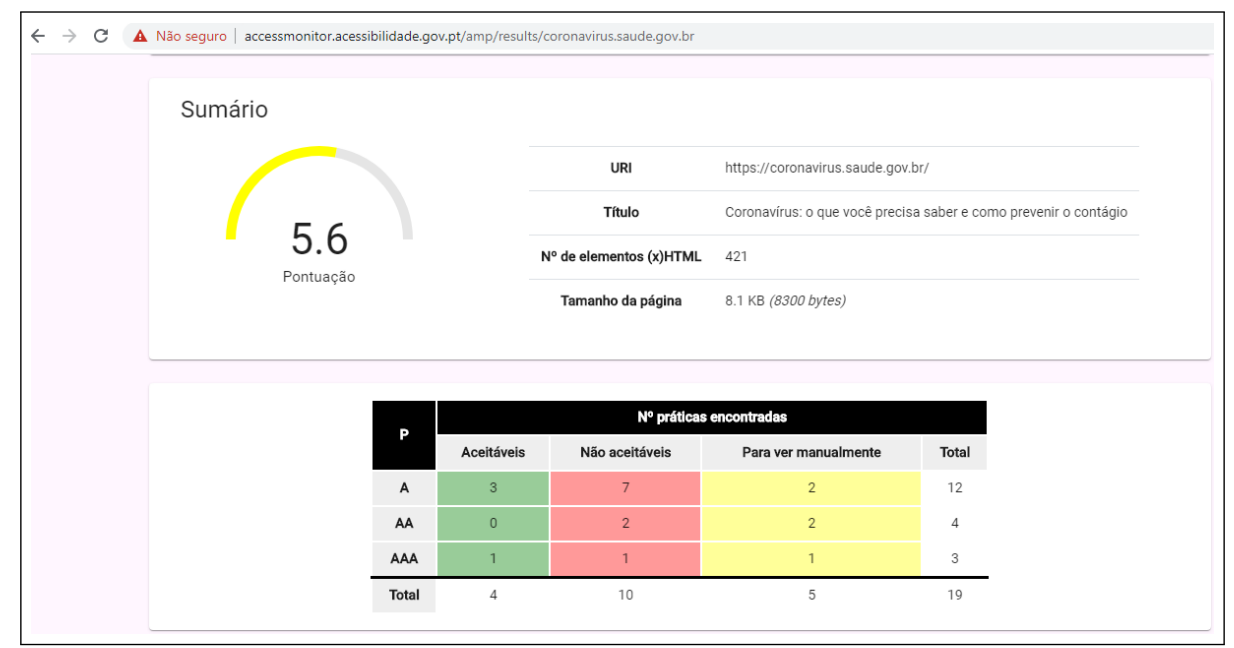

Figura 5. Avaliação de Acessibilidade.

Fonte: Ministério da Saúde (2020).

A página não atende a uma série de requisitos sem os quais determinados grupos de usuários não poderiam acessar as informações do ambiente informacional. O critério de sucesso deste nível é tornar acessíveis, por meio da utilização de uma alternativa em texto, as informações transmitidas por meio de conteúdo não textual.

Os desenvolvedores de websites, principalmente ambientes da área da saúde, devem fornecer as alternativas em texto para tornar as informações acessíveis, uma vez que podem ser apresentadas por meio de qualquer forma sensorial (por exemplo: visual, auditiva ou tátil) adequada às diversas necessidades dos sujeitos informacionais.

\footnotetext{
${ }^{1}$ Recuperado de http://accessmonitor.acessibilidade.gov.pt/amp/results/4.
} 
Outro ponto de destaque é ausência de leitor de tela para os usuários de baixa visão. A apresentação em Libras apresenta diversos problemas em sua estrutura e apresentação, pois as tentativas de abrir o link pelos pesquisadores foram falhas, já que esse parecia estar corrompido.

Portanto, confirma-se a falta de acessibilidade do ambiente informacional e ressalta-se que a sua estrutura precisa ser revista, com a inclusão de ferramentas adaptáveis a todos os tipos de sujeitos informacionais.

\section{Pontos positivos e negativos do website}

Com base na análise no ambiente informacional, por meio dos elementos da Arquitetura da Informação, apresentam-se os pontos positivos e negativos a serem melhorados na estrutura do website, em especial na página principal do ambiente, o que pode contribuir para o uso, a disseminação e a recuperação da informação.

\begin{tabular}{|l|l|}
\hline Pontos Positivos & Pontos Negativos \\
\hline $\begin{array}{l}\text { 1) Informações relevantes em formas de } \\
\text { questionamentos no tópico: "o que você } \\
\text { precisa saber". }\end{array}$ & $\begin{array}{l}\text { 1) As informações sobre o COVID-19 } \\
\text { não estão acessiveis aos deficientes vi- } \\
\text { suais. }\end{array}$ \\
\hline $\begin{array}{l}\text { 2) Painel de leitos e insumos do Ministé- } \\
\text { rio da Saúde. }\end{array}$ & $\begin{array}{l}\text { 2) Assinalam-se apenas os aspectos po- } \\
\text { sitivos da atuação do Governo Federal. }\end{array}$ \\
\hline $\begin{array}{l}\text { 3) Há um link indicando informações so- } \\
\text { bre o acesso a informação do governo } \\
\text { federal. }\end{array}$ & $\begin{array}{l}\text { 3) Informações discrepantes com rela- } \\
\text { ção aquelas relatadas pela imprensa na- } \\
\text { cional e internacional. }\end{array}$ \\
\hline $\begin{array}{l}\text { 4) Apresenta um painel com notícias atu- } \\
\text { alizadas sobre o tema. }\end{array}$ & $\begin{array}{l}\text { 4) Omissão de dados e ausência de um } \\
\text { sistema de busca na página principal. }\end{array}$ \\
\hline $\begin{array}{l}\text { 5) Possui link que direciona ao download } \\
\text { do aplicativo "Coronavírus - SUS". }\end{array}$ & $\begin{array}{l}\text { 5) A página inicial apresenta muitos pai- } \\
\text { néis informacionais de tipos distintos, } \\
\text { sem organização de identificação. }\end{array}$ \\
\hline
\end{tabular}

Quadro 3. Listagem de pontos positivos e negativos sob o ponto de vista dos pesquisadores. Fonte: Dados da pesquisa (2020).

O Quadro 3 apresenta cinco pontos positivos e cinco pontos negativos acerca da arquitetura informacional do website analisado, referente à perspectiva do usuário. Com relação ao terceiro ponto positivo listado, o website apresenta um link que direcione o acesso à informação do governo federal. Mesmo sendo considerado um aspecto positivo, uma vez que ao menos direciona para uma página de pesquisa, deve-se rever a possibilidade desse sistema estar disponível de maneira mais clara, sem necessariamente estar alocado em omissão e dependente de outro link que, por sua vez, também não está em posição de destaque na página.

Com relação ao quarto ponto positivo, mesmo em se tratando de um painel que contém informações atualizadas acerca do tema em questão no contexto brasileiro, existe uma tendência de notícias expedidas apenas pelos demais websites do Ministério da Saúde, mas, não dos demais veículos da imprensa.

Quanto ao link de direcionamento ao download do aplicativo "Coronavírus-SUS", considera-se um feito importante e necessário. Ademais, aprecia-se que esse link também atribui destaque à descrição e funcionalidade do aplicativo, que visa conscientizar a população sobre o novo coronavírus, trazendo informativos de diversos tópicos como os sintomas, como se prevenir, o que fazer em caso de suspeita e infecção, além de um mapa indicando as unidades de saúde próximas.

A partir dos pontos negativos listados no Quadro 3, destaca-se que o quinto ponto negativo, "A página inicial apresenta muitos painéis informacionais de tipos distintos, sem organização de identificação", trata de uma crítica à quantidade exacerbada de diferentes tipos de informação contidos na página inicial do website, visto que é possível que o usuário se sinta confuso com a quantidade de links e com a falta de organização dos tipos informacionais emitidos. Além disso, destaca-se a ausência de um sistema de busca na página principal, dificultando os sujeitos informacionais na recuperação das informações.

No próximo subtópico da pesquisa, será proposto o wireframe do website, levando-se em consideração as análises realizadas até aqui, a fim de contribuir significativamente para a arquitetura informacional em questão.

\section{Wireframe do website}

Decorrente das análises da arquitetura da página inicial do ambiente informacional Coronavírus Brasil, este estudo propôs um novo wireframe para o website analisado, de modo a manter a estrutura do site oficial, mas, realizando-se algumas adequações. De um modo geral, pode-se dizer que a AI já está consolidada no âmbito da CI, com pesquisas aplicadas em ambientes informacionais digitais, podendo-se evidenciar sua aplicação em websites de saúde ou no campo da saúde. A título de exemplificação, podemos citar: Silva e Dias (2008), Telles, Nepomuceno, Ayres, e Natansohn (2009),Sales, Faria, Pinto, e Sousa (2016) e Brito, Puerta-Díaz, Oliveira, 
Martínez-Ávila, e Vidotti (2019). No entanto, por ser um assunto novo, o mesmo não ocorre no cenário da COVID-19 e, portanto, essa é a inovação trazida por esta pesquisa.

A versão original da página e, respectiva proposta, são apresentadas, a seguir, para favorecer uma análise comparativa delas.

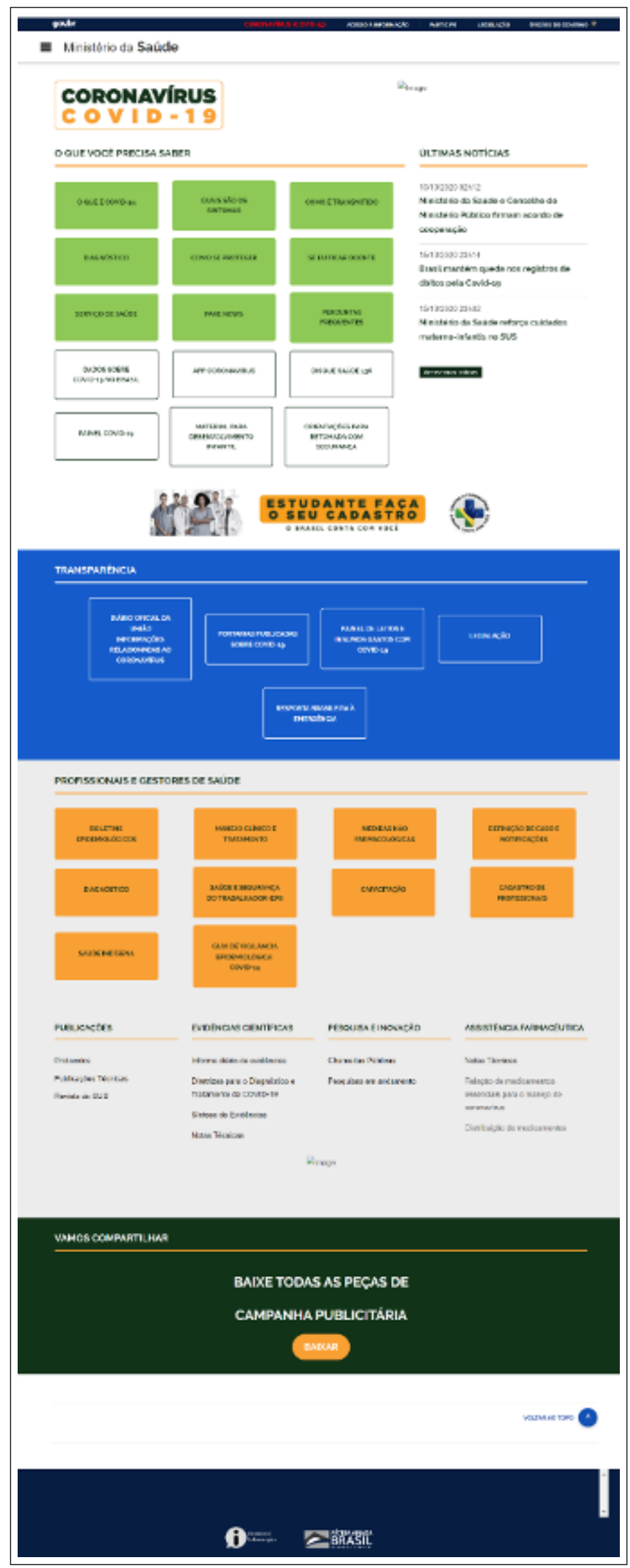

Figura 6. Versão original da página principal do website do Coronavírus Brasil: o que você precisa saber e como prevenir o contágio. Fonte: Ministério da Saúde (2020). 
A Figura 7 mostra o protótipo desenvolvido.
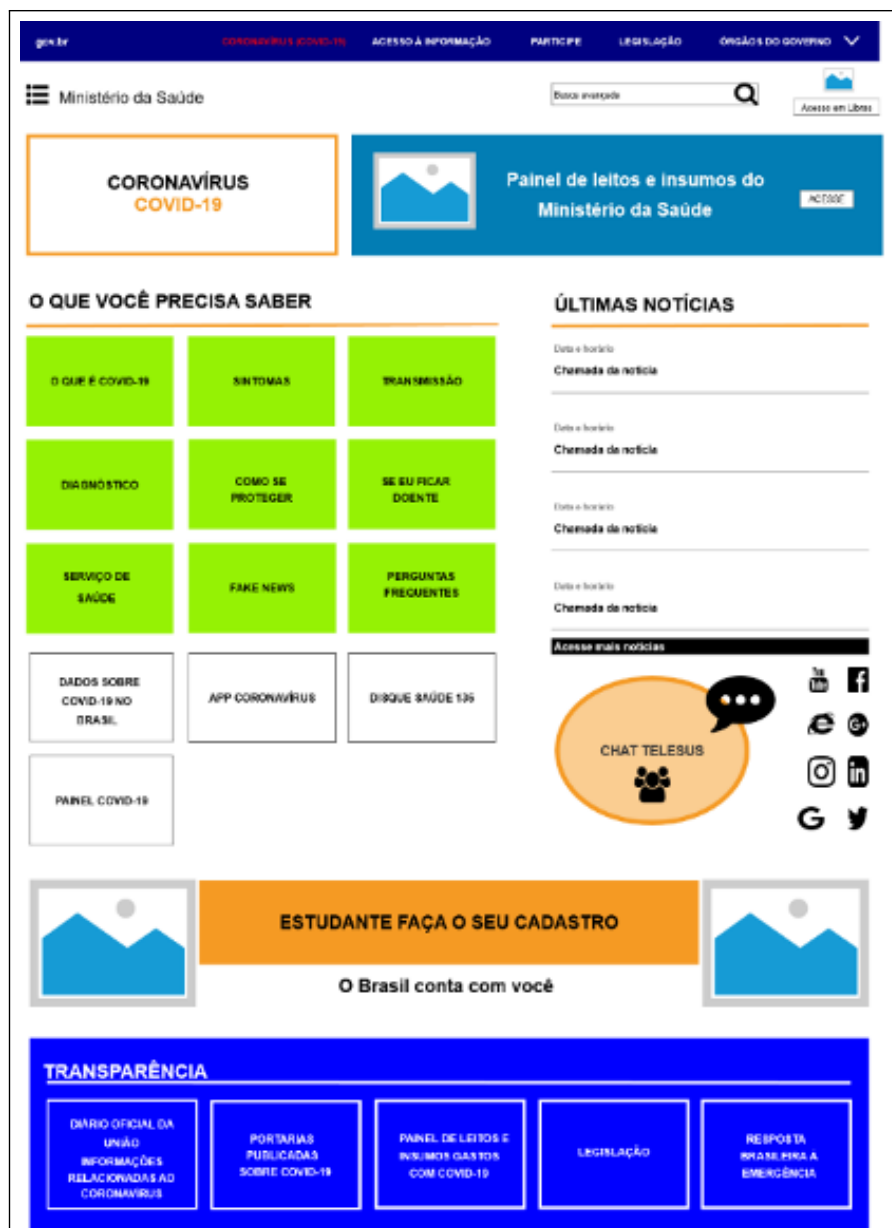

\section{O QUE VOCÊ PRECISA SABER}

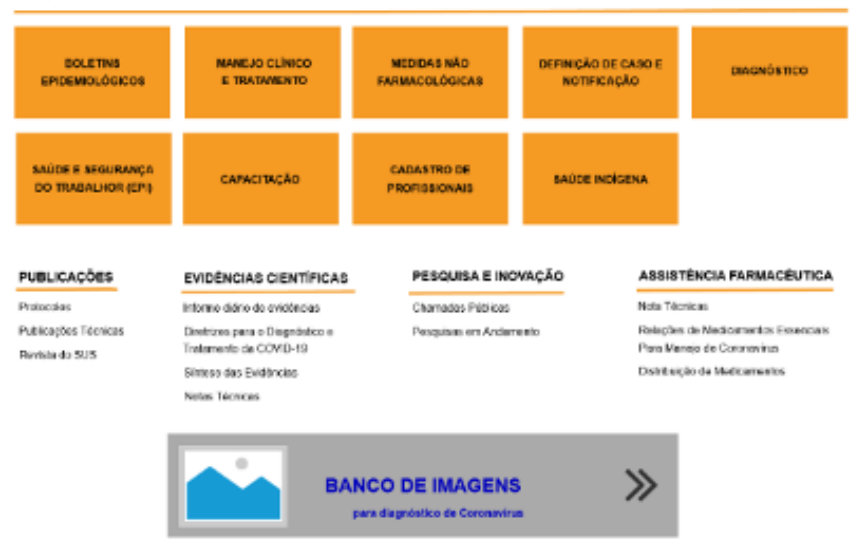

\section{TRANSPARÊNCIA}

\section{BAIXE TODAS AS PEÇAS DE \\ CAMPANHA PUBLICITÁRIA \\ ENXAR}
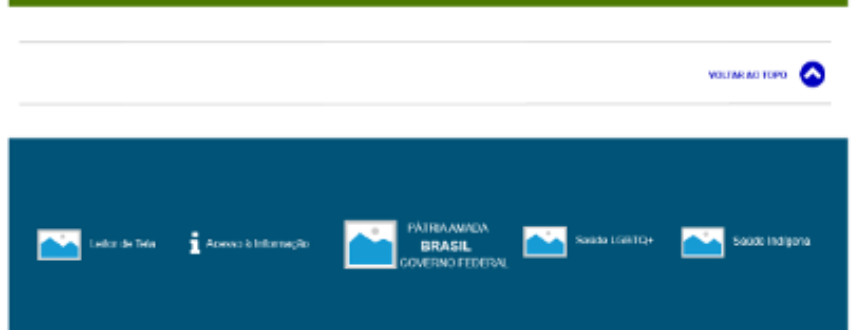

Figura 7. Proposta de wireframe para a página principal do website do Coronavírus Brasil: o que você precisa saber e como prevenir o contágio. Fonte: Elaborado pelos autores (2020). 
Como é possível observar, logo no início da página, foi inserido um campo de busca avançada, a fim de suprir a ausência dessa ferramenta no formato anterior. Ressalta-se que o sistema de busca auxilia o usuário no processo de busca por informações relevantes à sua pesquisa, poupando o seu tempo ao permitir com que o sistema recupere as informações delimitadas por ele.

O elemento "Acesso em Libras" foi deixado em destaque ao lado do sistema de busca, de modo que o usuário com deficiência auditiva possa se integrar ao conteúdo do website de maneira proativa logo que abrir a página. No ambiente informacional oficial, esse elemento é flutuante e decorre toda a página, acompanhando o mouse e a navegação do usuário, o que, muitas vezes, pode atrapalhá-lo em suas buscas, já que, conforme se mexe o mouse, o item referente ao elemento tampa palavras e outros ícones da página. Portanto, nesse caso, não se recomenda o uso de itens flutuantes. O mesmo acontece com o ChatTeleSUS, que será descrito no próximo parágrafo.

O elemento "ChatTeleSUS", originalmente chamado de CoronavírusTeleSUS, foi denominado dessa maneira para que o usuário possa entender que se trata de um chat. O seu design iconográfico foi modificado, de modo a chamar a atenção do usuário para o elemento. Para tanto, foram usados ícones referentes ao compartilhamento de informação e bate-papo. Ele foi fixado logo após as notícias, de modo a ficar em local de destaque no ambiente informacional.

Ao lado do ChatTeleSUS, optou-se por aderir ícones de redes sociais e outros navegadores, a fim de demonstrar a interligação das informações disponibilizadas no website para com a veracidade dos fatos disseminados pela mídia. Além disso, é possível fazer hiperlinks entre as redes sociais do Governo Federal relacionadas ao coronavírus e tal ambiente.

Quanto aos demais elementos do website, ressalta-se que eles foram distribuídos de uma forma mais harmônica, se comparados ao original, para dar à página uma ideia de limpeza e, assim, facilitar a encontrabilidade de informações. Esse é o caso da distribuição dos retângulos nos itens "Transparência" e "O que você precisa saber", por exemplo.

Para repensar o sistema de rotulagem do ambiente analisado, inseriram-se mais imagens ao website, em especial na parte final da página, onde, além do elemento "Acesso à Informação" e do logo "Pátria Amada Brasil" (já presentes no website oficial), foram colocados os elementos "Leitor de Tela" (para a inclusão de usuários com deficiência visual - item de acessibilidade), "Saúde LGBTQ+" e "Saúde Indígena".

Dessa maneira, buscou-se mostrar que, em um ambiente informacional tão importante quanto o analisado e, levando-se em conta os diversos públicos brasileiros, é necessário que o website seja mais inclusivo. Por serem itens ainda não presentes na plataforma oficial e que demandariam, para além de uma mudança na arquitetura da mesma, um acordo institucional, foram colocados como uma possível opção e, dessa forma, no final do wireframe.

\section{CONSIDERAÇÕES FINAIS}

Entende-se que, numa guerra com ameaças visíveis, à medida que se enxerga o inimigo, é mais fácil lutar contra ele. Numa pandemia, o inimigo existe, porém, não é visível ao olho nu, e muitos têm dificuldade de enxergar aquilo que não veem, ou seja, o não concreto. Posto isto, o Ministério da Saúde precisa aproveitar-se de todos os recursos midiáticos e didáticos para disseminar a informação em saúde, fazendo com que os cidadãos se apropriem mais facilmente dela. E, para tanto, tem que pensar na heterogeneidade da população brasileira, nos aspectos educacionais, culturais, cognitivos, entre outros, que devem ser levados em consideração num país de proporções gigantescas com infinitos regionalismos.

Nessa perspectiva, na contemporaneidade, a internet é uma via imprescindível à disseminação e ao acesso à informação. Contudo, um website governamental, que entre tantas informações, traga as relacionadas ao contexto pandêmico, deve possuir uma arquitetura propícia, objetivando-se contemplar o maior número de pessoas que vivam no território brasileiro e que possam ter acesso ao celular e/ou computador com acesso à internet. Porém, os resultados de análise na sua página inicial mostraram uma incoerência na arquitetura do ambiente informacional do Coronavírus Brasil, diante de tantos pontos que dificultam o acesso à informação aos diferentes tipos de sujeitos informacionais. Embora o ambiente informacional apresente uma arquitetura responsiva, ou seja, adaptativa a dispositivos móveis, não leva em conta algumas limitações dos sujeitos que dele se apropriam.

Parte dessa problemática incide quando o próprio Estado, que deveria proteger o cidadão, cria meios ardilosos de disseminação e acesso à informação, como, por exemplo, ao omitir informações referentes ao número de infectados da COVID-19 no território brasileiro. Dessa maneira, o ambiente informacional analisado, além de ser pouco atrativo para a maioria dos cidadãos, tendo sérios problemas estruturais e, consequentemente, baixa acessibilidade, possui problemas relacionados ao conteúdo disponibilizado, o que pode constituir-se como improbidade administrativa.

Tendo em vista esse cenário, a proposta de wireframe desenvolvida nesse estudo, levou em consideração os sistemas de organização, navegação, rotulagem e busca, além da acessibilidade do ambiente informacional do 
Coronavírus Brasil. Assim, uma interface mais amigável foi projetada, de modo a facilitar o acesso e uso efetivo das informações disponibilizadas no website, premissas essas pautadas na Arquitetura da Informação. Para trabalhos futuros, pretende-se ampliar o estudo da arquitetura nas páginas secundárias.

\section{AGRADECIMENTOS}

Agradecemos à FAPESP, CAPES e CNPq pelo apoio à pesquisa. 


\section{REFERÊNCIAS}

Almeida, G. B. C., Sousa, A. K. N. d., \& Oliveira, H. P. C. (2018). Arquitetura da informação no contexto de gênero: uma análise do website da secretaria especial de políticas para mulheres. Ciência da Informação em Revista, 5(3), 30-42. Recuperado de https://www.seer.ufal.br/index.php/ cir/article/view/5601.

Brito, J. F. d., Puerta-Díaz, M., Oliveira, L. P. d., MartínezÁvila, D., \& Vidotti, S. A. B. G. (2019). Uma análise da arquitetura da informação no website da associação nacional de travestis e transexuais (antra). In Viii seminário em ciência da informação. Londrina: UEL. Recuperado de http://www.uel.br/eventos/cinf/index.php/secin2019/ secin2019/paper/view/573.

Camargo, L. S. A., \& Vidotti, S. A. B. G. (2011). Arquitetura da informação: uma abordagem prática para o tratamento de conteúdo e interface em ambientes informacionais digitais. Rio de Janeiro: LTC.

Constituição da República Federativa do Brasil de 1988. (2019). Constituição da república federativa do brasil de 1988. São Paulo: Revista dos Tribunais.

Ferreira, A. M. J. F. d. C. (2018). Contribuições da experiência do usuário para a arquitetura da informação. (Tese de doutorado). Universidade Estadual Paulista, Brasil.

Marietto, M. L. (2018). Observação participante e não participante: contextualização teórica e sugestão de roteiro para aplicação dos métodos. Revista IberoAmericana de Estratégia, 17(4), 5-18. doi: 10.5585/ ijsm.v17i4.2717.

Ministério da Saúde. (2020). Coronavírus covid - 19. Recuperado de https://coronavirus.saude.gov.br/.

Moresi, E. (2003). Metodologia de pesquisa. Brasília: Universidade Católica.

Murray, K. B. (1991). A test of services marketing theory: consumer information acquisition activities. Journal of Marketing, 55(1), 10-25. doi: 10.2307/1252200.

Rosenfeld, L., Morville, P., \& Arango, J. (2015). Information architecture: for the web and beyond. Sebastopol, CA: O'Reilly.

Sales, O. M. M., Faria, G. B. d., Pinto, V. B., \& Sousa, M. R. F. d. (2016). Arquitetura da informação: estudo e análise da base de dados public medical (pubmed). Biblios(63). Recuperado de https://www.redalyc.org/ jatsRepo/161/16146347001/html/index.html.

Santos, B. R. P. (2019). Gestão da informação no setor público de saúde: um estudo em unidades de saúde da família (Dissertação de mestrado, Universidade Estadual Paulista Júlio de Mesquita Filho, Brasil). Recuperado de http:// hdl.handle.net/11449/180948.

Silva, P. M. d., \& Dias, G. A. (2008). A arquitetura da informação centrada no usuário: estudo do website da biblioteca virtual em saúde (bvs). Encontros Bibli, 13(26). Recuperado de https://www.redalyc.org/pdf/147/14712794009.pdf.

Spink, A., \& Case, D. O. (2012). Looking for information. Bingley: Emerald.

Telles, C. S., Nepomuceno, H., Ayres, M., \& Natansohn, G. (2009). Arquitetura da informação nos sites tpm e boa forma. In Intercom, xi congresso de ciências de comunicação na região nordeste. Teresina, Piauí: Sociedade Brasileira de Estudos Interdisciplinares da Comunicação. Recuperado de http://www.intercom.org.br/papers/regionais/ nordeste2009/resumos/R15-0156-1.pdf.
Vechiato, F. L. (2010). Repositório digital como ambiente de inclusão digital e social para usuários idosos. (Dissertação de mestrado, Universidade Estadual Paulista, Brasil). Recuperado de https:// repositorio.unesp.br/bitstream/handle/11449/93616/ vechiato_fl_me_mar.pdf? sequence $=1 \&$ isAllowed $=\mathrm{y}$.

Vechiato, F. L., \& Vidotti, S. A. B. G. (2009). Subsídios teórico-metodológicos para a construção de ambientes informacionais digitais. In A ciência da informação criadora de conhecimento. Coimbra: Imprensa da Universidade de Coimbra.

Vidotti, S. A. B. G., Cusin, C. A., \& Corradi, J. A. M. (2008). Acessibilidade digital sob o prisma da arquitetura da informação. In Ensino e pesquisa em biblioteconomia no brasil: a emergência de um novo olhar. São Paulo: Cultura Acadêmica.

Vitorino, E. V., \& Piantola, D. (2011). Dimensões da competência informacional. Ciência da Informação, 40(1), 99-110. Recuperado de http://revista.ibict.br/ciinf/article/ view/1328/1507.

Wilson, T. D. (1997). Information behavior: an interdisciplinary perspective. Processing \& Management, 33(4), 551-572. doi: 10.1016/S0306-4573(97)00028-9.

Yafushi, C. A. P. (2015). A competência em informação para a construção do conhecimento no processo decisório: estudo de caso na duratex de agudos (sp) (Dissertação de mestrado, Universidade Estadual Paulista Júlio de Mesquita Filho, Brasil). Recuperado de http://hdl.handle.net/11449/ 126599 .

Brito, J. F., Silva, R. C. da, Santos, B. R. P. \& MartínezÁvila, D. (2020). Arquitetura da informação no contexto da informação em saúde: um olhar para o website da Covid-19 no Brasil. AtoZ: novas práticas em informação e conhecimento, 9(2), 183 - 195. Recuperado de: http://dx.doi.org/10.5380/atoz.v9i2.75091 